\title{
Reverse logistics network optimizing by genetic algorithm: a case study of automotive wiring harnesses
}

\begin{abstract}
The shortage of material and environmental legislations have encouraged car manufacturers to recycle used material in end of life vehicles (ELVs), reverse logistics are essential to the concerns of the automotive supply chain. In this research, a profit model multi-echelon reverse logistics network including collection center, shredder center and recycling center is developed to recycle automotive parts. The work was continued by illustrating empirical application in wiring harness manufacturer that would like to recycle wire harnesses and extract copper. With regards to the complexity of the reverse logistics network, traditional method cannot be implemented for solving them. Thus, an evolutionary algorithm based genetic algorithm (GA) is applied as a solution methodology to solve mixed integer linear programming model and find the optimum solution. The results emphasize the efficiency of the modeling and solving method so that in the case study the company gained more than 27 thousand dollars through the establishment of reverse logistics for recycling copper.
\end{abstract}

Keyword: Automotive wiring harnesses; Genetic algorithm; Meta-heuristic algorithms; Recycling; Reverse logistics; Supply chain 